\title{
Erratum to: Temperature control and readout circuit interface for Mox based $\mathrm{NH}_{3}$ gas sensor
}

Dharmendra Kumar Sharma ${ }^{1}$ Rama Sai Vinay Dwara ${ }^{3}$ B. A. Botre Re $^{1,2}$ S. A. Akbar ${ }^{1,2} \cdot$ Kaushal Kishore $^{1,2}$

Published online: 11 May 2017

(C) Springer-Verlag Berlin Heidelberg 2017

Erratum to: Microsyst Technol (2017) 23:1575-1583

DOI 10.1007/s00542-016-3126-6

Unfortunately, a co-author's name was not listed in the original publication. The missing author name and affiliation is given below:

Kaushal Kishore

\section{Affiliations}

1. CSIR-Central Electronic Engineering Research Institute (CSIR-CEERI), Pilani, India

2. Academy of Scientific and Innovative Research (AcSIR), Chennai, India

The online version of the original article can be found under doi:10.1007/s00542-016-3126-6.

Dharmendra Kumar Sharma

dharmendra0034@gmail.com

1 CSIR-Central Electronic Engineering Research Institute (CSIR-CEERI), Pilani, India

2 Academy of Scientific and Innovative Research (AcSIR), Chennai, India

3 BITS Pilani Hyderabad Campus, Hyderabad 500078, India 